einstein

Publicação Oficial do Instituto Israelita

de Ensino e Pesquisa Albert Einstein

ISSN: 1679-4508 | e-ISSN: 2317-6385
ARTIGO ORIGINAL

\section{Quando a cor ajuda}

\author{
When color helps
}

Ana Luiza Fontes de Azevedo Costa', Thiago Gonçalves dos Santos Martins², Ricardo Vieira Martins ${ }^{3}$, Paulo Schor ${ }^{4}$

\footnotetext{
1 Hospital das Clínicas, Faculdade de Medicina, Universidade de São Paulo, São Paulo, SP, Brasil.

2 Universidade Federal de São Paulo, São Paulo, SP, Brasil.

${ }^{3}$ Universidade Federal do Rio de Janeiro, Rio de Janeiro, RJ, Brasil.

${ }^{4}$ Escola Paulista de Medicina, Universidade Federal de São Paulo, São Paulo, SP, Brasil.
}

DOI: 10.31744/einstein_journal/2019A04410

\section{RESUMO}

Objetivo: Reduzir a identificação errônea de colírios, por meio do uso de substâncias com cores diferentes. Métodos: Um grupo de 34 voluntários saudáveis foi apresentado a dois grupos de quatro colírios cada. Todos os colírios foram colocados em frascos idênticos sem rótulo. Em um grupo de quatro colírios, todos tinham conteúdos transparentes. No outro grupo, cada um dos quatro possuía uma substância de cor diferente. A cada um foi atribuído um número, e o voluntário foi solicitado a identificá-lo por meio da cor. Medimos o índice de acerto na identificação dos colírios dos dois grupos. Resultados: Os voluntários possuíam nível de formação desde Fundamental incompleto até Pós-Graduação completa, sendo 16 do sexo masculino (48\%) e 18 do sexo feminino (52\%), com idades variando de 21 até 87 anos. 0 índice de acerto no grupo de colírios coloridos foi de $88 \%$ e, no grupo de colírios transparentes, de $24 \%$. Conclusão: 0 uso de colorações em colírios pode auxiliar na diferenciação entre os frascos e prevenir a identificação errônea.

Descritores: Soluções oftálmicas; Segurança do paciente; Cor; Comportamento do consumidor; Rotulagem de medicamentos/métodos; Embalagem de medicamentos/métodos

\section{ABSTRACT}

Objective: To reduce the inappropriate identification of eye drops, through the use of different colors. Methods: A group of 34 healthy volunteers was presented to two groups of four eye drops each. All eye drops were placed in identical, unlabelled vials. In one group, all four eye drops were transparent. In the other group, each had a different color. A number was assigned to each eye drop, and the volunteer was asked to identify it by color. We measured the correct index in the identification of the eye drops of the two groups. Results: The volunteers had a level of education from incomplete junior school to complete graduate course, with 16 males (48\%) and 18 females $(52 \%)$, age range of 21 to 87 years. The success rate in the group of colored eye drops was $88 \%$ and, in the group of transparent, $24 \%$. Conclusion: The use of colorings in eye drops can help distinguishing the vials and preventing misidentification.

Keywords: Ophthalmic solutions; Patient safety; Color; Consumer behavior; Drug labeling/methods; Drug packaging/methods

\section{INTRODUÇÃO}

Ao longo da evolução, os fotorreceptores retinianos foram se modificando para permitir a sobrevivência dos mamíferos, que modificaram seus hábitos de noturno para diurno. Os seres humanos possuem três tipos de cones, que são fotorreceptores capazes de absorver diferentes comprimentos de onda: curta, média e longa (azul, verde e vermelho, respectivamente).(1) 
O ser humano é capaz de distinguir algo em torno de 16 milhões de cores. Esta percepção depende da ativação dos cones em diferentes intensidades. A visão de cores é um recurso importante, que permitiu aos seres humanos avaliarem melhor o meio ambiente em sua complexidade. Além disso, contribui para a memorização de cenas visuais. ${ }^{(2)}$

Considerando a importância das cores na identificação do ambiente, notamos que elas poderiam ser um atributo útil para auxiliar na diferenciação entre os variados tipos de colírios que apresentam atualmente coloração transparente e embalagens muito similares.

O uso incorreto de colírios é um problema encarado por inúmeros pacientes. Muitas vezes, é pouco reconhecido pelo próprio paciente, que não tem consciência do erro, e pelo profissional de saúde, que não possui controle da forma como o paciente utiliza o colírio no dia a dia.

Ao avaliar os frascos de colírios presentes no mercado, observamos que os colírios de uma mesma empresa possuem frascos muito semelhantes. Mesmo com a visão preservada, a troca de colírios pode ocorrer, até mesmo com remédios de uso sistêmico que dispensam gotas. Mesmo quando as tampas possuem cores diferentes, pode haver troca das tampas, levando ao uso incorreto. $^{(3,4)}$

\section{OBJETIVO}

Reduzir a identificação equivocada de colírios por meio do uso de diferentes cores para identificá-los.

\section{MÉTODOS}

Foi realizado um ensaio clínico com amostra randomizada. Os 34 participantes foram selecionados de forma aleatória. O exame oftalmológico prévio foi realizado, sendo excluídos aqueles que tivessem algum acometimento da acuidade visual ou da percepção de cores.

O protocolo de estudo foi aprovado pelo Comitê de Ética em Pesquisa da Faculdade de Medicina da Universidade Federal de São Paulo, número 2.408.088, CAAE: 60480115.7.0000.5505.

Os 34 voluntários foram apresentados a oito colírios em dois grupos de quatro colírios (Figura 1). Os colírios estavam em frascos idênticos, mas possuíam substâncias diferentes. O primeiro grupo de colírios possuía substâncias de cores diferentes (fluoresceína sódica $1 \%$ de cor amarela; uma lágrima artificial contendo vitamina B12 de cor rosa; acetato de prednisolona $1 \%$ de cor branca; e tartarato de brimonidina $0,1 \%$ transparente). O segundo grupo de colírios era composto por substân-

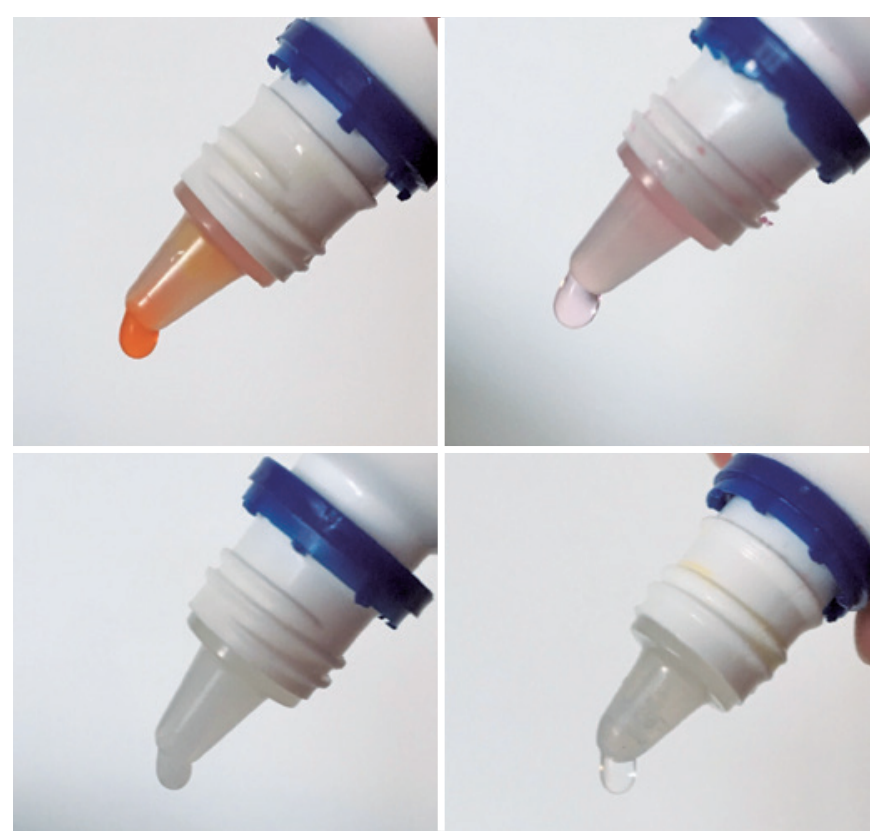

Figura 1. Colírios com substâncias de cores diferentes utilizados no teste de identificação

cias transparentes (carmelose sódica $5 \mathrm{mg} / \mathrm{mL}$, fumarato de cetotifeno $0,25 \mathrm{mg} / \mathrm{mL}$, tropicamida $10 \mathrm{mg} / \mathrm{mL}$ e hialarunato de sódio $0,15 \%$ ). Os frascos foram numerados em suas bases (de forma que o voluntário não pudesse ver), de acordo com a cor e a substância. Um papel com o número e o nome da substância foi oferecido ao voluntário, de forma que não foi necessária memorização. Somente quem estava aplicando o teste sabia o número e a substância de cada frasco apresentado. Os participantes foram, então, solicitados a informar o número correspondente à substância de cada frasco. Os números de acertos de cada participante foram transferidos para planilha eletrônica Microsoft Excel 2002 e submetidos a testes estatísticos.

\section{| RESULTADOS}

Os voluntários possuíam nível de formação desde fundamental incompleto até Pós-Graduação completa, sendo 16 do sexo masculino (48\%) e 18 do sexo feminino $(52 \%)$, com idades variando de 21 ate 87 anos. O índice de acerto no grupo de colírios coloridos foi de $88 \%$ e, no grupo de colírios transparentes, de $24 \%$.

\section{| DISCUSSÃO}

Durante o estudo, avaliamos colírios de diversas empresas e percebemos que substâncias de funções diversas possuem frascos muito parecidos, aumentando o risco de confusão durante a aplicação do colírio. Esta con- 
fusão pode ser feita tanto pelo próprio paciente como pela pessoa que aplica a medicação. O uso de substâncias indevidas, além de não causar o efeito desejado do tratamento, pode levar a efeitos colaterais graves, como queimaduras oculares, quando há confusão com medicações sistêmicas em gotas. ${ }^{(5)}$

Colírios de diferentes cores podem servir como um alerta, caso o paciente ou auxiliar manuseei o frasco incorreto. Neste momento, pode ser realizada a troca da medicação ou tomada alguma atitude imediata, em caso de uso incorreto.

A utilização de colorações em colírios poderia ser útil, sendo, porém, necessário considerar o risco do uso de corantes, naturais ou artificiais, já que é possível haver alteração farmacodinâmica e farmacocinética induzida por tais substâncias. Por este motivo, as colorações adotadas precisam ser cuidadosamente selecionadas e estudadas, para garantir que não existirá dano à superfície ocular ou qualquer modificação na droga ativa do colírio. Todas as substâncias utilizadas em nosso teste eram atualmente comercializadas no Brasil. Novas medicações, com cores mais facilmente identificáveis, poderiam ser produzidas com este objetivo.

Uma limitação deste estudo foi a proximidade com a qual normalmente se utiliza o colírio para pacientes que utilizam o próprio colírio, pois a distância é reduzida, e o foco acaba ficando prejudicado, impedindo a identificação correta das cores. Neste caso, a identificação seria melhor realizada pelo auxiliar responsável por pingar o colírio no paciente, que observaria a gota de uma distância mais adequada. Além disso, é necessária iluminação adequada para determinação das cores.

Em nosso ensaio, as diferentes colorações ajudaram pessoas com visão preservada e a uma distância na qual se podia manter um bom foco a identificarem melhor as medicações. Outros artifícios, como capas flexíveis de texturas e cheiros distintos, podem ser usados nos frascos de colírios também para auxiliar na identificação, atendendo pacientes com visão comprometida permanentemente ou até temporariamente, como em pós-operatórios. ${ }^{(6)}$

\section{CONCLUSÃO}

A coloração da substância pode ser um fator de auxílio à identificação, principalmente quando em uma distância adequada para manter o foco. Futuros estudos devem ser realizados para determinar quais colorações podem ser utilizadas sem prejuízo da farmacocinética das drogas e sem toxicidade para a superfície ocular.

\section{INFORMAÇÃO DOS AUTORES}

Costa AL: http://orcid.org/0000-0002-6925-4207

Martins TG: http://orcid.org/0000-0002-3878-8564

Martins RV: http://orcid.org/0000-0003-2455-4852

Schor P: http://orcid.org/0000-0002-3999-4706

\section{REFERÊNCIAS}

1. Price TD, Khan R. Evolution of visual processing in the human retina. Trends Ecol Evol. 2017;32(11):810-13. Review.

2. Lent R. Cem bilhões de neurônios? Conceitos fundamentais de Neurociência. 2a ed. Rio de Janeiro: Atheneu; 2010

3. Steinemann TL, Brown MF. Inadvertent instillation of nonophthalmic antiseptic drops due to packaging similarity. Arch Ophthalmol. 1998;116(9):1246.

4. Frenkel RE, Hong YJ, Shin DH. Misuse of eye drops due to interchanged caps. Arch Ophthalmol. 1988;106(1):17.

5. Labetoulle M, Frau E, Le Jeunne C. Systemic adverse effects of topical ocular treatments. Presse Med. 2005;34(8):589-95. Review.

6. Costa AL, Martins TG, Martins TG, Schor P. Multisensory eyedrop bottle sleeves for better identificantion of eye-drops. Insight. 2016;41(3):16. 